\title{
Wind turbines site selection on an isolated island
}

\author{
L.-I. Tegou, H. Polatidis \& D. A. Haralambopoulos \\ University of the Aegean, Department of Environment, \\ Energy Management Laboratory, Greece
}

\begin{abstract}
Site selection is a critical issue for wind energy projects, with particular limitations in cases of isolated islands. This paper develops an integrated framework to evaluate land suitability for wind turbine siting that combines multi-criteria analysis (MCA) with geographical information systems (GIS); an application of the proposed framework for the island of Lesvos, Greece is further illustrated. A set of environmental, economic, social, and technical constraints, based on recent Greek legislation, is used to limit the potential sites for wind power installation. The remaining area is evaluated by a variety of factors, such as wind power potential, land use, electricity demand, visual impact, land value, and distance to electricity grid. The analytic hierarchy process (AHP) method is applied to estimate the factors' weights in order to establish their relative importance in site evaluation. The overall suitability of the study region for wind turbine siting is appraised through the use of the simple additive weighting (SAW) method.

A collateral scope of this study is the consideration of the most updated Greek legislation for renewable energy facilities siting, in order to investigate the influence of specific factors on site suitability. Results showed that only $1.3 \%$ of the total area of Lesvos could be viable for wind turbine installation, although favourable wind potential exists in bigger parts of the island.

Keywords: wind turbine siting, geographical information systems, multi-criteria analysis, analytic hierarchy process.
\end{abstract}

\section{Introduction}

Renewable energy sources (RES) tend to be highly site-specific, therefore it is important to know where they are available in addition to numerical assessment. 
Wind farm siting constitutes an important phase in wind power development. As a result, energy and electricity industry professionals and policy groups have developed a variety of studies and strategies for mitigating siting difficulty for new power plants [1].

In recent years geographical information systems (GIS) have become increasingly popular as a tool for the selection of optimal sites for different types of activities and installations. GIS are not only computer systems designed to produce maps, but also powerful tools of geographical analysis. A GIS is a system of hardware, software, and procedures to facilitate the acquisition, management, manipulation, analysis, modeling, representation, and output of spatially referenced data to solve complex planning and management problems [2]. Applications of GIS to RES planning include wind farm siting, photovoltaic electrification, or biomass evaluation stand out [2-8].

Multicriteria evaluation (MCE) is one of the most common GIS based strategies that have been designed to facilitate decision making in site selection, land suitability analysis, and resource evaluation [9]. The analytic hierarchy process (AHP) method, originally developed by Saaty [10], is one of the most flexible and easily implemented MCE techniques and its use has been largely explored in the literature with many examples in locating facilities [2, 4, 11-16] The popularity of the AHP method in giving solutions to a multi-criteria problem is attributed to the fact that it takes into consideration both tangible and intangible criteria [11]. When the AHP method is applied to solve spatial decision problems in a GIS environment it is called spatial-AHP method [17].

The aim of this paper is to develop an integrated framework for the selection of optimal sites for wind turbines installations, in an electricity autonomous area, taking into account all of the restrictions enforced by legislation. A combination of weighted environmental, techno-economic, and social factors is used to evaluate the study area in order to bring out the most economically feasible and environmental friendly locations for wind projects implementation. The AHP method is used to estimate the weight of each factor.

This paper continues as follows: Section 2 presents an outline of the methodological framework, while section 3 describes an application of this framework to the Island of Lesvos, Greece. The results of the application are discussed in section 4. Finally, concluding remarks are included in section 5.

\section{Description of methodology}

Site selection for wind turbines requires consideration of a comprehensive set of factors in determining the suitability of a particular area for a defined land use. These factors involve bounding constraints that comprise of physical, technical, economic, environmental and cultural issues, and criteria that represent a yardstick or means by which a particular option can be evaluated as more desirable than another. These constraints and evaluation criteria influence the selection of potential sites. The constraints are based on the Boolean relation (true/false), which limit the research area to particular sites. The evaluation criteria define a degree of continuous measure of suitability for all the 
geographic regions [18]. The particular spatial analysis involved here can be achieved through either raster or vector GIS, however a raster GIS is preferred considering its wider mathematical capabilities [19].

The first stage of the methodology addresses the issue of defining the bounding constraints. Depending on their type, a buffer zone is required to define the minimum/maximum distance of development sites from a particular geographical feature. The width of buffer zones varies according to the specific constraint. A binary GIS grid is created for each constraint, with cells falling within a constrained area assigned " 0 " and the rest of them assigned " 1 ". By multiplying all constraint layers (CL), a final constraint map is calculated representing the areas that are restricted from development of wind power facilities. Only the cells with value " 1 " in each input layer will have non-zero value in the final constraint map.

In the next phase, the evaluation criteria that score potential sites are defined and represented as a map layer in a GIS database, namely evaluation layer (EL). In order to allow direct comparability, the ELs should be standardized. The 'maximum score procedure' is a linear scale transformation method that converts data into standardized criterion scores [9]. It uses the eqn (1) for a given benefit criterion (that should be maximized) and eqn (2) if the criterion should be minimized (cost criterion) [9]:

$$
\begin{aligned}
x_{i j}^{\prime} & =\frac{x_{i j}}{x_{j}^{\max }} \\
x_{i j}^{\prime} & =\frac{x_{j}^{\min }}{x_{i j}}
\end{aligned}
$$

where $\mathrm{x}_{\mathrm{ij}}^{\prime}$ is the standardized score for the $i^{\text {th }}$ cell and $j^{\text {th }}$ criterion; $x_{i j}$ is the score of this cell; $x_{j}^{\max }$ is the maximum score of the $j^{\text {th }}$ criterion and $\mathrm{x}_{\mathrm{j}}^{\text {min }}$ is the minimum score for the $\mathrm{j}^{\text {th }}$ criterion. These standardized scores range from 0 to 1 .

All evaluation criteria are not equally important in influencing the selection of potential sites. The AHP method is used to assign appropriate weights to the criteria reflecting their relative importance. This method was selected because of its simplicity and ability to deal with qualitative/subjective data $[4,11]$.

The AHP is based on pair-wise comparisons, which are used to determine the relative importance of each criterion. The first step of this method is to structure the decision problem in a hierarchy. The goal of the decision is on the top level of the hierarchy; the next level consists of the criteria relevant to the decision problem; at the third level are the alternatives (e.g. sites) to be evaluated [4]. The second step is the comparison of criteria in order to rank the alternatives. By comparing a pair of criteria at a time using a verbal scale, decision makers can quantify their opinions about the criteria magnitude [12]. It uses a fundamental nine point's scale measurement to express individual preferences or judgments (table 1), creating a reciprocal ratio matrix. Specifically, the weights are determined by normalizing the eigenvector associated with the maximum eigenvalue of the reciprocal ratio matrix [9]. 
Table 1: $\quad$ The fundamental scale of pair-wise comparisons in AHP $[9,10]$.

\begin{tabular}{|c|l|}
\hline Intensity of Importance & \multicolumn{1}{|c|}{ Definition } \\
\hline 1 & equal importance \\
\hline 2 & weak or slight \\
\hline 3 & moderate importance \\
\hline 4 & moderate plus \\
\hline 5 & strong importance \\
\hline 6 & strong plus \\
\hline 7 & very strong or demonstrated importance \\
\hline 8 & very to extreme strong \\
\hline 9 & extreme importance \\
\hline
\end{tabular}

The AHP also provides mathematical measures to determine inconsistency of judgments. Based on the properties of reciprocal matrixes, a consistency ratio (CR) can be calculated. In a reciprocal matrix, the largest eigenvalue $\left(\lambda_{\max }\right)$ is always greater than or equal to the number of rows or columns (n). If a pair-wise comparison does not include any inconsistencies, $\lambda_{\max }=\mathrm{n}$. The more consistent the comparisons are, the closer the value of computed $\lambda_{\max }$ to $\mathrm{n}$. A consistency index (CI) that measures the inconsistencies of pair-wise comparisons can be written as [10]:

$$
\mathrm{CI}=\left(\lambda_{\max }-n\right) /(n-1)
$$

and a measure of coherence of the pair-wise comparisons can be calculated in the form of consistency ratio (CR)

$$
\mathrm{CR}=(\mathrm{CI} / \mathrm{RI}),
$$

where RI is the average CI of the randomly generated comparisons [10]. As a rule of thumb, a CR value of $10 \%$ or less is considered as acceptable. Otherwise a re-voting of comparison matrix has to be performed $[4,20]$.

Since the criterion weights have been estimated, the Simple Additive Weighting (SAW) method is used in order to compute an overall suitability index for each cell of the study area. In specific, each EL is multiplied with the respective weight. The weighted evaluation layers are simply summed in order to provide a total performance score for each cell. SAW ranks cells from the highest to the lowest score. In GIS, this technique results in the overall evaluation map, which is multiplied with the constraint map in order to produce the final evaluation map. The mathematic formulation of the method is described by eqn (5) [21]:

$$
S_{i}=\sum_{j=1}^{n} w_{j} v_{i j}
$$

where $\mathrm{S}_{i}$ is the suitability index for cell $i, w_{j}$ is the relative importance weight of criterion $j, v_{i j}$ is the grading value of cell $i$ under criterion $j$, and $n$ is the total number of criteria.

Based on GIS spatial analysis, AHP approach and SAW method, the assessment procedure of wind turbine siting is presented in fig.1. 


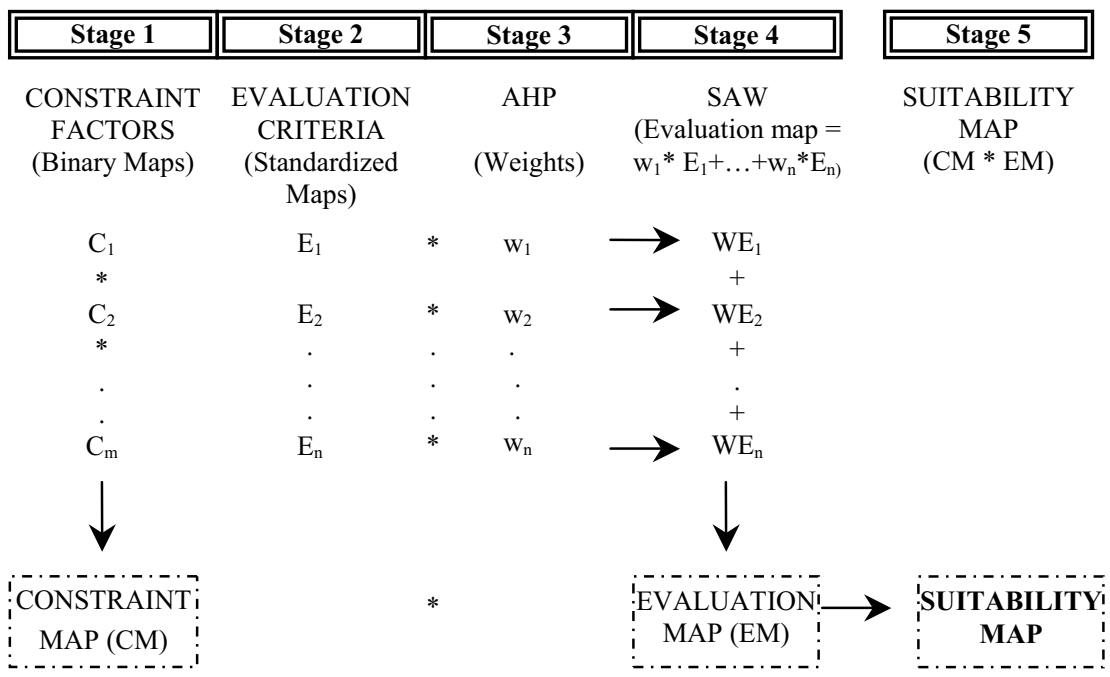

Figure 1: The methodological framework of wind turbine siting.

In the next section an application regarding the siting of wind turbines in the island of Lesvos is unfolded.

\section{Case study}

\subsection{Study area}

Lesvos Island is located in the northeast of Greece, in the Aegean Sea. Its total area is $1636 \mathrm{~km} 2$, with 90,436 inhabitants (census of 2001). Agriculture and tourism are the main economic activities on the island. Electricity production on Lesvos Island is based on an autonomous grid which is powered by a conventional oil station owned by the Public Power Corporation (PPC). This power plant is fuelled by fuel and diesel oil and is located in the outskirts of Mytilene. Wind potential on the island is high and PPC and other private and municipal investors have employed it for electricity generation, but these projects have so far managed to exploit only a small fraction of the island's full wind capacity. Other RES, i.e. geothermal and solar, have also been developed but on a very limited scale.

\subsection{Application of methodology}

For the implementation of the research the "Vestas V52-850 kW" wind turbine was selected, with the following specifications: height $(\mathrm{H})=44 \mathrm{~m}$, rotor's diameter $(\mathrm{D})=52 \mathrm{~m}$. According to current legislation the minimum distance between two wind turbines must be $3 * \mathrm{D}$, so the selected cell size in raster maps is $3 * \mathrm{D}=156 \mathrm{~m}$. The GIS software used here is ArcGIS 9.2. 


\subsubsection{Generation of constraint map}

Constraint factors in this study were selected according to recent Greek legislation for RES siting [23]. In particular, ten (10) constraint maps were produced according to the constraint factors presented in table 2 .

Table 2: Constraint factors and evaluation criteria.

\begin{tabular}{|l|l|l|l|}
\hline \multicolumn{2}{|c|}{ Constraint factors } & \multicolumn{2}{c|}{ Evaluation criteria } \\
\hline C1 & Petrified Forest & E1 & visibility \\
\hline C2 & wetlands & E1a & visibility from settlements \\
\hline C3 & NATURA 2000 & E1b & visibility from historic areas \\
\hline C4 & high productivity agricultural land & E2 & land value \\
\hline C5 & slope angles $>30 \%$ & E3 & slope \\
\hline C6a & settlements & E4 & land use \\
\hline C6b & distance from settlements* & E5 & wind potential \\
\hline & - traditional $>1500 \mathrm{~m}$ & E6 & distance from road network \\
\hline & - significant $>1000 \mathrm{~m}$ & E7 & distance from electricity grid \\
\hline & other $>500 \mathrm{~m}$ & E8 & electricity demand \\
\hline C7a & historic areas & & \\
\hline C7b & distance from historic areas $>500 \mathrm{~m}$ & & \\
\hline C8 & distance from monasteries $>500 \mathrm{~m}$ & & \\
\hline C9 & distance from road network $<10000 \mathrm{~m}$ & & \\
\hline C10 & wind potential $<4 \mathrm{~m} / \mathrm{s}$ & & \\
\hline
\end{tabular}

*Due to the unique cultural features of most Greek settlements, Greek legislation has characterized them as "traditional", "significant" and "other" according to their cultural importance.

For the factors $\mathrm{C} 1, \mathrm{C} 2, \mathrm{C} 3, \mathrm{C} 4, \mathrm{C} 5, \mathrm{C} 6 \mathrm{a}, \mathrm{C} 7 \mathrm{a}$, and $\mathrm{C} 10$, the corresponding binary constraint maps are produced by the simple procedure of reclassification embedded in the ArcMap. When siting in an area is prohibited the relative map cell is valued as ' 0 '; otherwise it is valued as ' 1 '. For C9 a buffer zone with width $10000 \mathrm{~m}$ is created and the areas out of this zone are valued as " 0 ". It should be mentioned that according to national legislation constraints $\mathrm{C} 6 \mathrm{~b}, \mathrm{C} 7 \mathrm{~b}$ and C8 apply only to visible wind turbines [23]. Therefore, initially a buffer zone for each is created with width according to data presented in table 2; subsequently, each map cell is evaluated in terms of visibility from a set of given points of interest (settlements, historic sites, monasteries), through the use of viewshed function of ArcMap (OFFSETA=1.5, OFFSETB=44, RADIUS2=radius of buffer zone) and the relevant visibility maps are generated. The produced maps are reclassified, and the multiplication of all binary constraint maps calculates the total Constraint Map.

\subsubsection{Evaluation criteria}

Eight criteria were identified to score potential sites; they are also presented in table 2. A short description of these criteria follows:

E1 - Visibility: Greek legislation limits the number of visible wind turbines in an area close to a site of interest (SoI) (e.g. historical site, settlement) depending on the distance from this site. More specifically, the area next to a SoI is 
separated into three zones, A, B, C, with different radius each one for every type of SoI. Non-visible wind turbines are excluded from this limitation. Table 3 shows the number of permitted installed wind turbines in each zone on Lesvos Island. For the computation of E1, two (2) visibility maps have to be created; the settlements' visibility map (E1a) and the historical sites' visibility map (E2b).

Table 3: $\quad$ Permitted installed WT in each zone on Lesvos.

\begin{tabular}{|l|c|c|c|}
\hline \multicolumn{1}{|c|}{ Zone } & $\mathrm{A}$ & $\mathrm{B}$ & $\mathrm{C}$ \\
\hline \multicolumn{1}{|c|}{ site of interest } & \multicolumn{2}{|c|}{ radius of zones $(\mathrm{m})$} \\
\hline traditional settlements & 1500 & 3000 & 6000 \\
\hline significant settlements & 1000 & 3000 & - \\
\hline other settlements & 500 & 1000 & 2000 \\
\hline historical sites & 500 & 3000 & 6000 \\
\hline \multicolumn{1}{|c|}{ wind turbines $/ \mathrm{km}^{2}$} & 0 & 4 & 7 \\
\hline
\end{tabular}

The procedure for E1 a calculation is the following:

a) creation of a multiple buffer zone for each type of settlement, reclassification and union, union with shoreline

b) conversion to raster (cell size $=156 \mathrm{~m}$ )

c) reclassification, giving the following values:

$0 \rightarrow$ into settlement; $2 \rightarrow$ Zone $\mathrm{A} ; 4 \rightarrow$ Zone $\mathrm{B} ; 8 \rightarrow$ Zone $\mathrm{C}$

d) summation of reclassified map with visibility map (calculated previously)

e) reclassification, giving the following values:

$0 \rightarrow$ restriction; $5 \rightarrow$ Buffer3000 and visible; $7 \rightarrow$ Buffer6000 and visible;

$9 \rightarrow>$ Buffer6000 and visible; $10 \rightarrow$ non-visible

The "historical sites' visibility map" is calculated in same way. The two visibility maps have the same weight factor ( $50 \%$ each). Thus, visibility map $(\mathrm{E} 1)=\left(0,5^{*}\right.$ settlements' visibility map $)+\left(0,5^{*}\right.$ historical sites' visibility map)

E2 - Land Value: the evaluation is accomplished through these criteria:

(LV1) Municipal District coefficient, as defined by national legislation [24]; (LV2) distance from road network; (LV3) distance for shoreline; (LV4) land use.

The AHP method is used to determine the weights of these four criteria. Table 4 illustrates the pair-wise matrix.

Table 4: $\quad$ Pair-wise matrix of land value.

\begin{tabular}{|c|c|c|c|c|c|}
\hline Criteria & LV4 & LV2 & LV3 & LV1 & Weights \\
\hline LV4 & 1.000 & 0.333 & 0.200 & 0.111 & 0.051 \\
\hline LV2 & 3.000 & 1.000 & 0.500 & 0.200 & 0.129 \\
\hline LV3 & 5.000 & 2.000 & 1.000 & 0.333 & 0.233 \\
\hline LV1 & 9.000 & 5.000 & 3.000 & 1.000 & 0.587 \\
\hline \multicolumn{7}{|c|}{ Consistency Ratio $=0.014<0.1$} \\
\hline
\end{tabular}


Using the SAW method the land value map is produced by the equation: Land Value Map $(\mathrm{E} 2)=(0.051 *$ Land use $)+(0.129 *$ Dist. from road network $)+$ $(0.233 *$ Dist. from shoreline $)+(0.587 *$ Municipal District c. $)$

E3, E4, E5 - Slope, land use, wind potential: The initial maps are reclassified and evaluated giving the maximum values to the most suitable sites.

E6, E7 - distance from road network, distance from electricity grid: Multiple buffer zones per $100 \mathrm{~m}$ are created in order to evaluate the whole study area; the closer to the grid/road, the greater the value.

E8 - Electricity demand: It is estimated according to population growth and electricity consumption of the last 10 years. Data on population were taken from National Statistical Service of Greece (NSSN) and on electricity consumption from NSSN and PPC. The final map depicts the spatial electricity demand for the year 2025.

The EL are then standardized and the AHP method is used to estimate the relative weight of each criterion.

\subsubsection{Estimation of weights}

A pair-wise matrix for the estimation of the weights of the evaluation criteria is created and shown in table 5.

Table 5: $\quad$ Pair-wise matrix of evaluation map.

\begin{tabular}{|c|c|c|c|c|c|c|c|c|c|}
\hline Criteria & E2 & E3 & E1 & E8 & E7 & E6 & E4 & E5 & Weights \\
\hline E2 & 1.000 & 0.500 & 0.250 & 0.200 & 0.200 & 0.200 & 0.167 & 0.111 & 0.025 \\
\hline E3 & 2.000 & 1.000 & 0.500 & 0.333 & 0.250 & 0.250 & 0.200 & 0.167 & 0.039 \\
\hline E1 & 4.000 & 2.000 & 1.000 & 0.500 & 0.333 & 0.333 & 0.333 & 0.250 & 0.065 \\
\hline E8 & 5.000 & 3.000 & 2.000 & 1.000 & 0.500 & 0.500 & 0.333 & 0.333 & 0.095 \\
\hline E7 & 5.000 & 4.000 & 3.000 & 2.000 & 1.000 & 1.000 & 0.500 & 0.500 & 0.145 \\
\hline E6 & 5.000 & 4.000 & 3.000 & 2.000 & 1.000 & 1.000 & 0.500 & 0.500 & 0.145 \\
\hline E4 & 6.000 & 5.000 & 3.000 & 3.000 & 2.000 & 2.000 & 1.000 & 0.500 & 0.210 \\
\hline E5 & 9.000 & 6.000 & 4.000 & 3.000 & 2.000 & 2.000 & 2.000 & 1.000 & 0.276 \\
\hline & \multicolumn{7}{|c|}{ Consistency Ratio =0.024<0.1 } \\
\hline
\end{tabular}

The total evaluation map is calculated through the SAW method, described by the following formula:

Evaluation Map $=(0.025 * \mathrm{E} 2)+(0.039 * \mathrm{E} 3)+(0.065 * \mathrm{E} 1)+(0.095 * \mathrm{E} 8)+$ $(0.145 * \mathrm{E} 7)+(0.145 * \mathrm{E} 6)+(0.210 * \mathrm{E} 4)+(0.276 * \mathrm{E} 5)$

\section{Results}

The Suitability Map is derived from the multiplication of Constraint Map with Evaluation Map (Fig. 2). This operation is equivalent to cutting the restricted areas out of the map. 

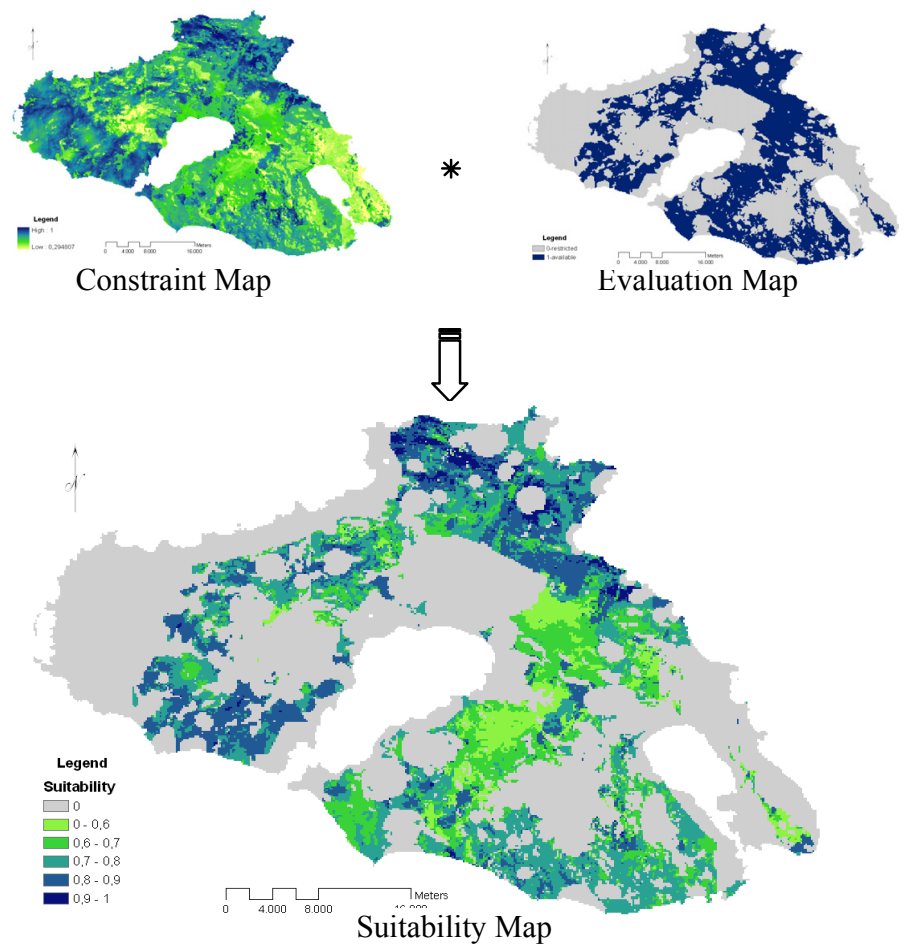

Figure 2: $\quad$ Map of suitability index.

The most appropriate areas for wind turbine siting are those shown in white, with suitability index $0.9-1$. Sites with $0.8-0.9$ index are also suitable, having, however, more disadvantages than the previous ones, i.e. higher costs, technical difficulties, intense but acceptable visual impact, etc. It is noticeable that over half of the entire study area $(56.9 \%)$ is restricted from wind turbine installation, while only a considerably small percentage (1.3\%) of the island's surface achieved the optimal suitability index (Fig. 3), even though wind potential is adequate in more areas (Fig. 4). Nevertheless, the best-ranked sites coincide with those with highest wind potential. This is mainly due to the significant weight of "wind potential" evaluation criterion.

The last step of the siting process is to evaluate local characteristics of high valued areas after field inspection, in order to verify their practical suitability.

\section{Conclusions}

This paper develops a GIS framework for wind turbine site selection based on the combination of the SAW and the AHP multi-criteria analysis methods; the developed framework is subsequently applied in Lesvos Island, Greece. 


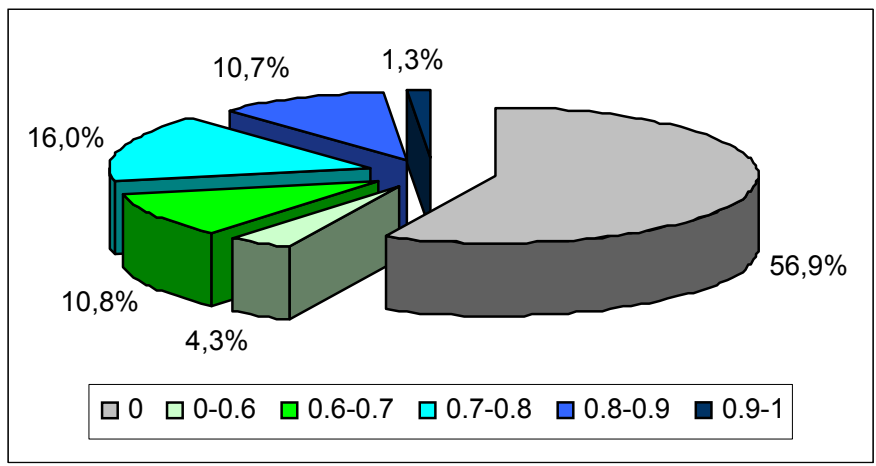

Figure 3: $\quad$ Suitability index.

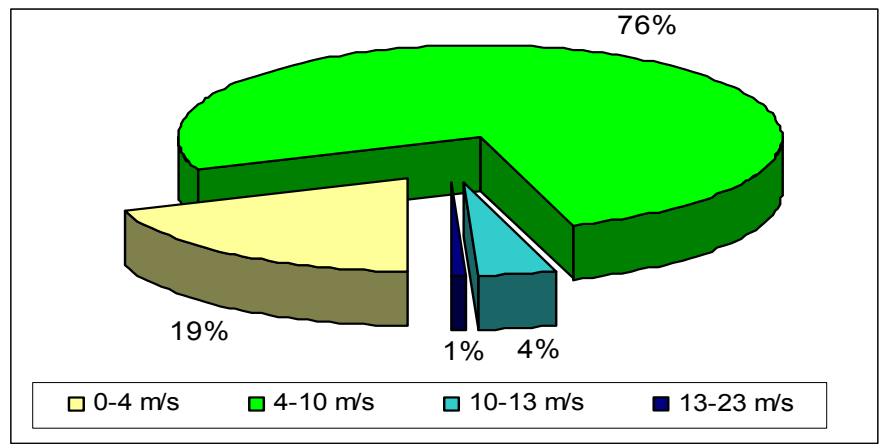

Figure 4: Wind potential.

The main objective is the maximization of the penetration of wind energy in a power grid and the mitigation of the impact of wind parks on the environment, economy, and society. Environmental, techno-economic, and social constraints and evaluation criteria were considered in the computation process. The AHP method was utilized to assign the relative importance weights of evaluation criteria, while the final suitability map for wind turbine siting was calculated through the SAW method. The results indicated the optimal locations for wind projects, excluding over $50 \%$ of the whole study region.

The constraint factors were developed according to standing legislation for non-grid connected islands. Energy planners may use this tool to determine locations for feasible wind turbine installation. The presented methodology, however, could be applied to other kinds of project siting since, due to its generic nature, it can incorporate a variety of criteria and constraints. 


\section{Acknowledgements}

This paper is part of the 03ED677 research project, implemented within the framework of the "Reinforcement Programme of Human Research Manpower" (PENED) and co-financed by National and Community Funds (20\% from the Greek Ministry of Development- General Secretariat of Research and Technology and 80\% from E.U.- European Social Fund).

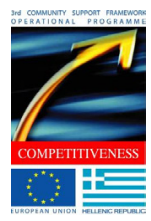

\section{References}

[1] National Commission on Energy Policy (NCEP), Siting critical energy infrastructure: An overview of needs ad Challenges. NCEP, Washington, D.C., 2006.

[2] Aran Carrion, J., Espin Estella, A., Aznar Dols, F., Zamorano Toro, M., Rodriguez, M. \& Ramos Ridao, A., Environmental decision-support systems for evaluating the carrying capacity of land areas: Optimal site selection for grid-connected photovoltaic power plants. Renewable and Sustainable Energy Reviews, 12, pp. 2358-2380, 2008

[3] Yapa, L., Is GIS appropriate technology? International Journal of Geographical Information Systems, 5, pp. 41-58, 1991.

[4] Ma, J., Scott, N., DeGloria, S. \& Lembo, A., Siting analysis of farm-based centralized anaerobic digester systems for distributed generation using GIS. Biomass and Bioenergy, 28, pp. 591-600, 2005.

[5] Masera, O., Ghilardi, A., Drigo, R. \& Trossero, M.-A., WISDOM: AGISbased supply demand mapping tool for woodfuel management. Biomass and Bioenergy, 30, pp. 18-637, 2006.

[6] Yue, C.-D. \& Wang, S.-S., GIS-based evaluation of multifarious local renewable energy sources: a case study of the Chigu area of southwestern Taiwan. Energy Policy, 34, pp.730-742, 2006.

[7] Rodman, L. \& Meentemeyer, R., A geographic analysis of wind turbine placement in Northern California. Energy Policy, 34, pp. 2137-2149, 2006.

[8] Ramirez-Rosado, J., Garcia-Garrido, E., Fernandez-Jimenez, L. A., Zorzano-Santamaria, P., Monteiro, C. \& Miranda, V., Promotion of new wind farms based on decision support system. Renewable Energy, 33, pp. 558-566, 2008.

[9] Malczewski, J., GIS and Multicriteria decision analysis, John Wiley \& Sons: New York, 1999.

[10] Saaty, T., The Analytic Hierarchy Process, McGraw-Hill: New York, 1980. 
[11] Aras, H., Erdogmus, S. \& Koc, E., Multi-criteria selection for a wind observation station location using analytic hierarchy process. Renewable Energy, 29, pp. 1383-1392, 2004.

[12] Kontos, Th., Komilis, D. \& Halvadakis, K., Siting MSW landfills with a spatial multiple criteria analysis methodology. Waste Management, 25, pp. 818-832, 2005.

[13] Tuzkaya, G., Onut, S., Tuzkaya, U.R. \& Gulsun, B., An analytic process approach for locating undesirable facilities: An example from Istanbul, Turkey. Journal of Environmental Management, 88, pp. 970-983, 2008.

[14] Dey, P.K. \& Ramcharan, E.K., Analytic hierarchy process helps select site for limestone quarry expansion in Barbados. Journal of Environmental Management, 88, pp. 1384-1395, 2008.

[15] Wang, G., Qin, L., Li, G. \& Chen, L., Landfill site selection using spatial information technologies and AHP: A case study in Beijing, China. Journal of Environmental Management, 2009.

[16] Nekhay, O., Arriaza, M. \& Guzman-Alvarez, J.R.: Spatial Analysis of the suitability of olive plantations for wildlife habitat restoration. Computers and Electronics in Agriculture 65 pp. 49-64, 2009.

[17] Siddiqui, M., Everet, J. \& Vieux, B., Landfill siting using geographical information systems: a demonstration. Journal of Environmental Engineering, 122, pp. 515-523, 1996.

[18] Hansen, H., GIS-based Multi-Criteria Analysis of Wind Farm Development. Proc. of the 10th Scandinavian Research Conference on Geographical Information Science (ScanGIS), Stockholm, Sweden, 2005.

[19] Pereira, J.M.C. \& Duckstein, L., A multiple criteria decision making approach to GIS based land suitability evaluation. International Journal of Geographical Information Systems, 7, pp. 407-424, 1993.

[20] Kablan, M.M., Decision support for energy conservation promotion: an analytic hierarchy process approach. Energy Policy, 32, pp. 1151-1158, 2004.

[21] Yoon, K. \& Hwang, C.L., Multiple Attribute Decision Making: an Introduction, Sage Publication Inc.: London, UK, 1995.

[22] Laboratory of Natural Disasters, Department of Geography, University of the Aegean, Greece.

[23] Hellenic Ministry of the Environment, Physical Planning and Public Works, Special regulatory framework for land-planning and sustainable development in renewable energy source, Athens, 2008.

[24] Hellenic Ministry of Economy and Finance, Ministerial Circular "ПОА.1068/3.4.2008", 2008. 